\title{
El comercio exterior de Indonesia en el marco de la apertura económica
}

$\mathrm{C}$ omo nación independiente a finales de la década de los cincuenta, Indonesia ha enfrentado diferentes escenarios en la búsqueda de un crecimiento económico sostenido, con el fin de elevar la calidad de vida de la población. A partir de 1965 ha experimentado importantes cambios en su política económica, motivados por acontecimientos internos y externos imprevistos que van desde cambios abruptos en los precios internacionales de sus principales productos hasta el embate de la naturaleza contra su territorio, con tsunamis y terremotos, y los movimientos separatistas de algunas de sus provincias.

Hasta mediados de los años ochenta, la orientación de la economía de Indonesia era "hacia adentro". Su principal prioridad fue lograr la autosuficiencia nacional en la mayor cantidad de productos posible, mientras sus exportaciones estuvieron basadas principalmente en el sector primario: específicamente en gas y petróleo (véase anexo: cuadro 1). En ese mismo periodo logró ser autosuficiente en el arroz, después de haber sido importador neto a mediados de los años setenta. La inversión mejoró la infraestructura del sector primario; se implementaron proyectos de capacitación de la población rural, en educación básica principalmente y se otorgaron subsidios a los fertilizantes, pesticidas y se mantu-

* Profesora-Investigadora del Departamento de Estudios del Pacífico de la Universidad de Guadalajara. vieron los precios internos por encima de los internacionales. Además, se mantenía un estricto control en las importaciones mediante el cobro de altos impuestos y la autorización de licencias especiales de importación que se otorgaban a los "importadores aprobados", generalmente se concedían a productores nacionales de los artículos que se pretendía importar.

El debilitamiento del precio internacional del petróleo de manera más acentuada a partir de 1982, obligó al país a buscar una nueva alternativa en el comercio internacional, pues la incertidumbre causada por la dependencia de las exportaciones del petróleo y el gas desencadenó innumerables desajustes en la economía indonesa. En 1984 los problemas originados por la elevada deuda externa (en 1980 el pago de la deuda representaba 13 por ciento de las exportaciones; en 1986 se incrementó a 40 por ciento) ${ }^{1}$ incidieron en la devaluación de la moneda de Indonesia, la rupia.

Así en los años ochenta, la situación de Indonesia ameritaba un giro radical en la economía que diera como resultado el crecimiento económico sostenido y certidumbre a los inversionistas nacionales y extranjeros. De esta forma surgió la necesidad de replantear su política económica con el fin de sortear la vulnerabilidad de que era objeto y se optó por escuchar las recomendaciones del Banco Mundial (BM) y del Fondo Monetario Internacional (FMI), ${ }^{2}$ que estuvieron orientadas a la apertura económica para la economía de Indonesia. 
Fue así que en 1986 se orientaron los esfuerzos hacia la apertura económica con el fin de ampliar y diversificar el comercio de productos elaborados con alto valor añadido y la creación de infraestructura que facilitara dicho proceso.

Indonesia sigue trabajando por una apertura gradual desde tres vertientes: de tipo multilateral, al adherirse a la Organización Mundial del Comercio (OMC); regional, al ser miembro activo de los acuerdos de la ASEAn (Asociación de Naciones del Sureste Asiático) ${ }^{3}$ y ASEAN+3 (Japón, China y Corea del Sur), y, por último, en el aspecto bilateral en agosto del presente año (2007) Indonesia firmó un Acuerdo de Libre Comercio con Japón (FTA, por sus siglas en inglés). ${ }^{4}$

El objetivo de este trabajo es presentar un panorama de los acontecimientos que motivaron transformaciones en la política económica de Indonesia en los años ochenta y los resultados de los cambios implementados. El artículo se divide en cuatro apartados: el primero trata sobre los acontecimientos que motivaron un cambio en la dirección de su economía; el segundo analiza la evolución de la apertura comercial y las condiciones en que se dio ésta; el tercero aborda la relación que guarda Indonesia con sus principales socios comerciales, y, por último, se hace alusión al comportamiento de la inversión extranjera directa (IED) y el papel que desempeña en la economía de Indonesia.

\section{Antecedentes históricos y la apertura económica de Indonesia}

Los acontecimientos que ha vivido Indonesia han servido como condición para dar inicio a la apertura económica, y muy particularmente la liberalización del comercio. William E. James y Sherry M.
Stephenson ${ }^{5}$ separan en tres periodos los hechos decisivos para orientar su política económica hacia la liberalización:

El primer periodo (1965-1972) se caracterizó por el inicio del gobierno del presidente Suharto (1966-1998) que, mediante la Agencia Nacional de Logística, tenía el monopolio de las importaciones y la distribución de materias a granel de productos como el trigo, el arroz, el azúcar y el frijol de soya, y se mantuvo un incremento desmedido de los precios de los productos. Sin embargo, a mediados del periodo, la inflación alcanzó 500 por ciento, en tanto que se vivía un caos político y un alto grado de corrupción. A finales de la década, gracias a las reformas gubernamentales introducidas — como la austeridad en el gasto público-, la inflación bajó a menos de 20 por ciento.

El segundo periodo (1973-1982) se distingue por el auge del petróleo, por mantener una economía cerrada y con precios flotantes en los productos energéticos (hasta 1978), debido a que la política económica conocida como "de orientación hacia adentro" dio prioridad a las importaciones de alta tecnología en la industria petroquímica (incluyendo equipo pesado de transporte, como aeronáutica o naval). Sin embargo, la crisis financiera de la empresa estatal de petroquímica "Pertamina" acentuó el problema de la inflación y el crédito internacional se vio afectado. En 1978 se devaluó la moneda con el fin de dar un empuje a las exportaciones manufactureras más eficientes (textiles y ropa) en ese momento.

En el tercer periodo, que inicia en 1983, el gobierno orientó los trabajos para abrir la economía al mundo, pero no fue sino hasta 1986 cuando logró concretarse y se dieron los primeros pasos para la apertura económica. La prioridad fue disminuir la 
dependencia de las exportaciones del petróleo; para ello fue prioritaria la atracción de inversión extranjera directa como fuente principal para diversificar el financiamiento de proyectos productivos en el país. El gobierno emprendió grandes reformas en la simplificación del comercio exterior: se dieron facilidades a la inversión (se otorgó un año de exención de impuestos en importación de equipo y se permitió 95 por ciento de inversión extranjera a las empresas orientadas a la exportación); se redujeron las barreras arancelarias y las no arancelarias; disminuyeron los requerimientos de visa; se redujeron las licencias de importación; se recortó el nivel de tarifas y se implementaron proyectos de desarrollo de infraestructura vital para las empresas orientadas a las exportaciones. La privatización alcanzó hasta 30 por ciento de participación en tres empresas cementeras del Estado. La respuesta de la economía fue muy favorable en términos de crecimiento económico, pero trajo consigo el resurgimiento de la inflación, que en ese momento se volvió la principal preocupación.

No obstante los esfuerzos por abrir la economía en pos de una mejoría en la actividad económica del país, a finales de 1997 y principios de 1998 se desencadenó la crisis financiera asiática, la cual tuvo efectos devastadores en la economía, retrasando las acciones encaminadas al logro de la apertura económica. Como resultado, se eliminaron los subsidios a los productos básicos; "el precio del petróleo, la electricidad y la gasolina aumentó 70 por ciento en menos de un año, el capital extranjero abandonó el país, la moneda nacional (rupia) se desplomó a finales de 1998, se desarrolló un desempleo masivo y entre 1999 y 2000 el 50 por ciento de la población quedó en la pobreza". ${ }^{6}$ Como consecuencia, el PIB real entre 1990-2001 creció un poco menos de 4 por ciento, después de haber crecido 6 por ciento en el decenio previo a la crisis. Una vez pasados los efectos inmediatos de la crisis financiera, en 2001 se inició la liberalización del sector petrolero y las empresas privadas empezaron a invertir en actividades de producción, comercialización, refinación, almacenamiento y en transporte de estos productos. Por lo tanto, "Pertamina" dejó de ser empresa exclusiva del gobierno de Indonesia.

Como parte de la estrategia de apertura, la participación de Indonesia en los foros internacionales es de vital importancia para el logro de sus objetivos de liberalización. En el acuerdo de Doha en 2002, Indonesia fijó su postura en varios puntos: en el campo de la agricultura abogó porque hubiera mayor consideración por las economías en desarrollo en el aspecto social y económico. Indonesia luchó por dejar fuera del paquete de liberalización a los productos sensibles, principalmente del sector agrícola; pugnó para que los países desarrollados disminuyeran su protección en las medidas sanitarias y fitosanitarias, las barreras técnicas al comercio, así como la implementación de subsidios y subvenciones a los productos agrícolas.

En el campo de los servicios, Indonesia ha presionado para que los países en desarrollo obtengan flexibilidad en el acceso a la apertura de mercados en el sector servicios, ya que es considerado como prio- 
ridad nacional para el desarrollo. También se planteó la necesidad de un formato de mecanismo de salvaguarda para proteger las industrias de servicios de los países en desarrollo.

La conferencia ministerial en Cancún, México, en septiembre de 2003, no dio los frutos esperados. Indonesia sugirió retomar los acuerdos de la reunión de Doha (sobre la reducción de subvenciones y subsidios a los productos agrícolas, específicamente en los países desarrollados) y quedó en espera de que los países desarrollados presten mayor atención a los puntos que son importantes para los países en vías de desarrollo y que cooperen en el logro de un buen balance en los acuerdos. También sugirió a los países desarrollados no forzar las negociaciones en materia de protección que coloquen en desventaja a los países en desarrollo.

La postura que asumió Indonesia en los foros internacionales tiene la finalidad de que las economías en desarrollo (grupo del cual forma parte Indonesia) tengan el tiempo y las condiciones necesarias para poder adaptarse al cambio originado por la apertura económica. De esta manera, espera poder robustecerse para algún día competir con las economías desarrolladas.

\section{Evolución de la apertura comercial de Indonesia}

Indonesia, en su condición de país en desarrollo y con base en las metas de Bogor acordadas en 1994 en el marco del Foro de Cooperación Económica Asia-Pacífico (APEC), pretende lograr en 2020 una apertura total del comercio de bienes y servicios, así como de la inversión extranjera. Sin embargo, hay interés en acelerar la integración regional con los miembros de la ASEAN y más allá de este grupo, con Chi- na, Corea del Sur y Japón principalmente, "poniendo como meta liberalizar en 2010 un primer bloque que abarca los siguientes sectores: tráfico aéreo, productos agrícolas, automóviles, comercio electrónico, pescado, productos basados en caucho, textiles y ropa, turismo y productos de madera; facilitación en el flujo de personas de negocios y mano de obra altamente calificada".

La meta de la ASEAN para 2020 es lograr una región estable, próspera, de alta competitividad, con un libre flujo de bienes, servicios, inversión y capital, a fin de alcanzar un desarrollo económico sostenido y reducir la pobreza y la desigualdad económica. En el mismo sentido, Indonesia tiene la intención de aplicar para 2020 el objetivo de la apertura comercial voluntario del APEC de un comercio de servicios e inversiones de forma abierta y libre, para las economías en desarrollo. ${ }^{8}$

Como ya se señaló, es a partir de 1986 cuando el gobierno indonés decidió liberalizar la economía. Sin embargo, lo ha hecho de manera cautelosa para reducir riesgos a los productores nacionales, principalmente los de productos considerados sensibles, a quienes encontramos en forma más frecuente en el sector agrícola. Es innegable la relevancia que ha tenido el sector agrícola, aunque en los últimos años la industria manufacturera ha ganado terreno en el sector productivo del país hasta lograr un valor de 47 por ciento en las exportaciones y cerca de 55 por ciento en las importaciones. El comercio de manufacturas tiene mayor peso en maquinaria y equipo de transporte; le siguen los productos químicos. Cabe hacer notar la importancia de acuerdo con el valor de las exportaciones que representa la industria textil en 2005 (véase anexo: cuadros 3 y 4).

Por su parte, los productos primarios en 2005 tuvieron un papel importante en 
el comercio internacional de Indonesia: cerca de 53 por ciento de sus exportaciones totales corresponden a ese sector, siendo la minería la que aporta el mayor porcentaje, superando así a los productos agrícolas alimenticios, tanto en las exportaciones como en las importaciones. La razón es que en el grupo de productos químicos se ubican el gas y el petróleo, que aún tienen un peso importante en la producción nacional (véase anexo: cuadros 3 y 4). No obstante que Indonesia es un país muy rico en recursos naturales, no ha sabido explotarlos con fines de abastecer la industria manufacturera para incrementar el valor agregado e involucrar a las empresas nacionales como abastecedoras de empresas transnacionales.

La protección agrícola que el gobierno se ha empeñado en mantener a pesar de las políticas de apertura, ha valido para que no se disparen las importaciones en este sector en perjuicio de los productores nacionales. Entre los productos con mayores niveles de protección se encuentran los agrícolas de consumo. En 2001 se decretó que el arroz, el clavo, el maíz, la soya y el azúcar sólo podrían ser importados mediante la concesión de una licencia especial de importación otorgada exclusivamente a los productores nacionales, ya que en su momento ellos podrían ser los más afectados con la liberalización. Además, en 2004 el gobierno de Indonesia instituyó la prohibición en las importaciones del arroz, azúcar y sal, y en 2005 se sumaron otro grupo de productos cuyo arancel de importación se incrementó: pescado, pollo, mango, zanahoria, naranja, mandarina, maíz, soya, flores y algunos productos de cerámica.

La protección también ha abarcado algunos casos de productos no agrícolas, como son los automóviles (la máxima ta- rifa es de 80 por ciento), hierro y acero y algunos productos químicos. Así algunos sectores (productos químicos, productos metálicos manufacturados, automóviles, productos alcohólicos, motocicletas y bicicletas) siguen sujetos a tipos arancelarios elevados, que llegan hasta 150 por ciento. En el sector de textiles y el vestido, el promedio de la protección arancelaria de Nación Más Favorecida (NMF) ha permanecido constante en 10.8 por ciento. ${ }^{9}$

Los tímidos esfuerzos de Indonesia por abrirse a los mercados internacionales han mostrado resultados poco significativos al respecto: la primera mitad de los años ochenta, cuando aún mantenía una economía con orientación hacia adentro, mostraba un porcentaje de exportaciones respecto al PIB de 25 por ciento aproximadamente, y que no dista mucho del promedio en los últimos cinco años de lo que va de 2000 (véase anexo: cuadro 1). El tipo de cambio elevado, que no se ha podido reponer de la drástica devaluación, indica que la economía todavía no se ha recuperado del todo y que aún le falta mucho por hacer para consolidarse a fin de obtener mejores resultados en el ámbito internacional. Sin embargo, sigue priorizando su estrategia de apertura en el ámbito regional.

En 2004 el gobierno de Indonesia, como miembro de la ASEAN y con el propósito de hacer un esfuerzo por contribuir a la integración de la región, lanzó un paquete de nueva reducción de tarifas: las tarifas no-ASEAN y las tarifas ASEAN. La mayoría de las tarifas no-ASEAN cayeron a 0,5 y 10 por ciento, excepto para partes para autos y alcohol. Las tarifas ASEAN cayeron en tres escaladas, $0,2.5$ y 5 por ciento para todos los bienes incluidos en la asociación. De esta forma, la predisposición por incrementar el comercio con la región es más que evidente. 
En resumen, las exportaciones de Indonesia han experimentado un cambio estructural importante, aunque su grado de apertura (medido por la participación de las exportaciones en el PIB) no ha alcanzado al de sus vecinos en ASEAN. Mientras que por varias décadas las exportaciones estuvieron concentradas en gas y petróleo (a mediados de los años setenta llegaron a representar 70 por ciento de las exportaciones totales de ese país), en los últimos años la dependencia de las exportaciones en esos productos se reduce gradualmente hasta llegar a 6.6 por ciento en 2005 (véase anexo: cuadro 1). Hoy, aunque las exportaciones de gas y petróleo siguen formando parte del grupo de productos de mayor exportación de Indonesia, otros productos del sector manufacturero adquieren mayor importancia relativa, tales como los aparatos eléctricos, los productos textiles, los minerales, los productos de la madera y papel y diversos productos agrícolas básicos.

Esto ha sido el resultado del crecimiento del sector manufacturero, el cual en 2006 representó 28 por ciento del PIB (después de que en 1980 apenas constituía 13 por ciento), mientras en las exportaciones su participación se ha quintuplicado al lograr representar 64 por ciento. De igual forma, el sector servicios se ha visto favorecido por el impulso de viajes y turismo: en 2006 representó 40 por ciento del PIB y el empleo se incrementó a 38 por ciento de la población activa. ${ }^{10}$

\section{La relación comercial de Indonesia con sus principales socios dentro y fuera de la región de ASEAN}

Indonesia es miembro fundador de la ASEAN en 1967 junto con Malasia, Filipinas, Singapur y Tailandia. Posteriormente, se in- corporaron Brunei (1994), Vietnam (1995), Laos (1997), Myanmar (1997) y Camboya (1999). Desde sus inicios, este grupo de economías acordaron unir esfuerzos para lograr objetivos comunes. Tuvieron muy claro que uno de los principales motivos para conformar este grupo fue lograr un crecimiento económico sostenido, sin embargo no hubo una propuesta de apertura comercial entre las economías de la región. No fue sino hasta 1992 cuando los miembros de la ASEAN acordaron establecer una zona de libre comercio, por lo que optaron por reducir gradualmente las tarifas de los productos no agrícolas en un periodo de quince años, que inició en 1993, por lo que se espera que en 2008 queden libres de aranceles estos productos.

No obstante que Indonesia forma parte de este proceso de apertura de la ASEAN, en 2005 las exportaciones fuera de esta región representaron 81.5 por ciento y las importaciones 70 por ciento, es decir, el comercio intrarregional es todavía muy bajo. De las diez economías que componen la ASEAN, sólo Singapur figura - en tercer lugarentre los cinco socios más importantes de Indonesia. Después de Japón y Estados Unidos, aparecen China continental y Corea del Sur, entre los cuales se concentra 60 por ciento de las exportaciones totales de Indonesia (véase anexo: cuadro 2).

El panorama en las importaciones es muy parecido al de las exportaciones. Entre las economías fuente de las importaciones indonesas figuran Singapur, China continental, Estados Unidos y Corea del Sur, en orden de importancia, y representan 50 por ciento de las importaciones totales de Indonesia en 2005. China continental ha cobrado relevancia en el comercio de Indonesia. Entre 2001 y 2005 se han duplicado las exportaciones que Indonesia dirige a China, al pasar de 3.9 a 7.8. En 
las importaciones provenientes de China el cambio ha sido mayor: en 2002 China era el quinto socio proveedor de las importaciones de Indonesia y en 2005 ocupó el tercer lugar después de Japón y Singapur (véase anexo: cuadros 1 y 2).

Indonesia mantiene estrechos vínculos con la ASEAN, que tienen que ver con el progreso social y cultural que son necesarios para mantener la paz y la estabilidad en la región. Sin embargo, para lograr el progreso económico es necesario hacer alianzas con economías que proporcionen complementariedad y provean de insumos necesarios para afianzar la economía. Por tal motivo se observan vínculos como la ASEAN+3 (Japón, China y Corea del Sur) y la muestra fehaciente es la que se ha dado con la firma del Acuerdo de Libre Comercio entre Indonesia y Japón en agosto de este año.

Es importante señalar la estrecha relación que Indonesia sostiene con las economías de la ASEAN; sin embargo, dada la dinámica comercial que mantiene Indonesia con países que no pertenecen a la región, es necesario que establezca relaciones bilaterales formales, así como su participación en otras organizaciones regionales intergubernamentales que traigan beneficios a la economía de Indonesia.

\section{La inversión extranjera de Indonesia}

Como consecuencia de la crisis asiática, Indonesia experimentó la salida de la inversión extranjera directa (IED) en forma masiva, de lo cual aún no ha logrado recuperarse del todo. A pesar de los esfuerzos por lograr beneficios del comercio mediante la apertura económica, no se han obtenido óptimos resultados.

Una de las fases importantes en la apertura económica de Indonesia fue la desregulación de los bancos, recapitalización y privatizaciones de las empresas estatales. Sin embargo, el proceso ha sido lento y aún no hay certidumbre para los inversionistas locales y extranjeros, por lo que Indonesia no ha logrado la recuperación económica después de la crisis financiera. "La apertura económica ha sido débil, la falta de IED ha afectado a la industria; incluso se habla de la desindustrialización de Indonesia (principalmente la que es intensiva en mano de obra)". ${ }^{11}$

La reglamentación de las inversiones en Indonesia sigue basándose en la Ley de Inversiones Extranjeras de 1967 y la Ley de Inversiones Nacionales de 1968, las cuales no permiten que particulares ni empresas extranjeras posean tierras en el país (sólo en casos excepcionales las empresas tienen derechos restringidos a la posesión de tierras). En 2000 un decreto presidencial actualizó la clasificación de los sectores en los que la inversión está restringida, y los dividió en: sectores que están completamente vedados a la inversión extranjera; sectores que están abiertos a la inversión extranjera pero con la condición de que el inversor extranjero establezca una empresa conjunta con una entidad indonesia y sectores que están abiertos a las inversiones extranjeras pero con sujeción a determinados requisitos. ${ }^{12}$

Indonesia permite 100 por ciento de propiedad extranjera de los bancos, de acuerdo con el decreto firmado en 2000, que incluye requisitos de capital: cinco mil millones de rupias para las compañías domésticas y 10 millones de rupias para las compañías con un socio extranjero de empresas a riesgo compartido.

En 2006 las inversiones extranjeras directas autorizadas se han concentrado en la industria manufacturera, en particular la de productos químicos y farma- 
céuticos; los cultivos alimentarios y las plantaciones, así como en el transporte, el almacenamiento y las comunicaciones y la construcción. La mayor parte de las autorizaciones corresponde a inversiones directas de países asiáticos, en especial Malasia, Singapur, Corea del Sur y Japón. ${ }^{13}$ La inversión como porcentaje del PIB en promedio entre 1973-1985 fue de 25 por ciento y ascendió a 33 por ciento en el periodo 1986-1992.

El gobierno ha realizado reformas significativas en su política en el sector de las telecomunicaciones. Las dos empresas principales de Indonesia PT Telkom y PT Indosat se han vendido parcialmente a inversores privados. Se han adjudicado licencias competitivas para el suministro de servicios de telefonía móvil GSM, servicios de Internet y otros servicios de alto valor añadido.

\section{Conclusiones}

Después de más de 20 años de que Indonesia optó por abrir sus fronteras al exterior, las pautas del comercio no han cambiado de manera sustancial. A falta de condiciones propicias para abrir todos los sectores productivos al comercio exterior, decidió liberalizar el comercio en forma gradual. En la actualidad mantiene elevadas barreras arancelarias y no arancelarias en los productos agrícolas, principalmente.

El problema serio que enfrenta Indonesia es que el sector agrícola (incluyendo ganadería, pesca y silvicultura) es el menos competitivo en el país: en 2006 representó cerca de 13 por ciento del PIB y dio empleo a 44 por ciento de la fuerza laboral, lo que denota una baja productividad. Las exportaciones agropecuarias representan 16.7 por ciento del total (a pesar de que Indonesia es el mayor productor mundial de cocos y el segundo en almendras y aceite de palma y caucho natural, así como el tercero entre los principales productores de arroz) y 11.5 por ciento de las importaciones corresponden al sector. Es decir, la economía indonesa sigue siendo muy vulnerable a los vaivenes internacionales en los precios de los commodities por su alta dependencia de productos basados en recursos naturales.

Los resultados favorables en algunos indicadores de la economía no han sido suficientes para incrementar el nivel de vida de los más vulnerables; si bien en 2005 la inflación disminuyó a 6.6 por ciento, el precio del arroz tuvo un incremento de 30 por ciento por encima del precio internacional debido a la escasez resultante de la prohibición de la importación de este producto en 2004. Ésta es una medida de protección comercial que ha resultado muy cara para los grupos más vulnerables. Los expertos atribuyen a este hecho el incremento de la pobreza que se vive en Indonesia, debido a que este producto es el principal alimento de los pobres (los pobres gastan en arroz la cuarta parte de su ingreso).

La mayor parte de los cultivos de Indonesia son del tipo alimenticio: maíz y arroz. La desventaja es que el nivel de productividad es muy bajo respecto al resto de la economía, además de no invertir lo suficiente en la industrialización de materias primas agrícolas para abastecer la industria nacional y extranjera. El sector agrícola sigue siendo el más importante en términos de empleo, pero la productividad de la mano de obra en la agricultura es inferior a la quinta parte del nivel registrado en el resto de la economía.

La meta que se propuso el gobierno de Indonesia al plantear una política de apertura económica fue elevar el nivel de vida de los ciudadanos, pero no ha 
ocurrido así porque incrementar los ingresos de la población perteneciente a los estratos económicos elevados no es una política incluyente. Es muy probable que las nuevas políticas planteadas estén contribuyendo a la distribución no equitativa de los recursos del país y de esta manera seguir empeorando la situación de los que menos tienen. La tasa oficial de desempleo (4.8 por ciento en 1997) ha estado situada por encima de 9 por ciento desde 2002, alcanzando 11.2 por ciento en 2005 y 10.3 por ciento en 2006 (véase anexo: cuadro 1). Este fenómeno se atribuye al menor dinamismo de la industria manufacturera en el primer quinquenio del 2000, después de que fue el motor de crecimiento en los años anteriores.

La pregunta clave sigue siendo ¿cómo contrarrestar los efectos negativos de la globalización y que los beneficios se perciban en toda la población? Mientras la Organización de las Naciones Unidas calcula que Indonesia logró avanzar dos puntos en el Índice de Desarrollo Humano (entre 2003 y 2006 de 110 pasó a 108, respectivamente). La omc, en la Evaluación de las Políticas Comerciales de Indonesia de 2007 , señala que en Indonesia aumentó el número de personas que viven con menos de 17 dólares al mes (de 16 por ciento de la población que vivía con ese ingreso en 2005 , aumentó a 18 por ciento en 2006).

Creemos firmemente que hay mucho por hacer y que los indicadores que tienen un desempeño positivo podrían ser la punta de lanza para avanzar en el aspecto económico indonés. El hecho de que la inflación esté más o menos controlada disminuye la incertidumbre en inversionistas nacionales y extranjeros, y esto puede ser un buen principio para que mejoren las condiciones de empleo, junto con la adopción de las nuevas leyes laborales que se adapten a las exigencias relacionadas con la apertura económica y el aprovechamiento de las ventajas comparativas y competitivas del país (que cuenta con abundantes recursos naturales que podrían ser utilizados en la industria).

Parece que la orientación en la economía va en ese sentido, pero quizás haga falta involucrar a los empresarios indonesios con el fin de que los beneficios de la industria se queden en el país, además de seguir trabajando por erradicar la corrupción, así como hacer un análisis de los contenidos de las leyes laborales y de inversión extranjera directa. De nada sirven los grandes proyectos de apertura económica si no se trabaja en solucionar los problemas estructurales que aquejan a ese país. my

\section{Notas}

1. Ebrary, para más información consulte http:// www.worldinformation.com.

2. Stiglitz, Joseph, El malestar en la globalización, Taurus, 2004, tercera reimpresión.

3. Las economías que integran la ASEAN son: Brunei, Camboya, Indonesia, Laos, Malasia, Mianmar, Filipinas, Singapur, Tailandia y Vietnam.

4. Organización Mundial del Comercio, Examen de las Políticas Comerciales de Indonesia, 2007.

5. James, William E. y Sherry M. Stephenson, The Evolution of Economic Policy Reform; Determinants Sequencing and Reason for Success, 2005.

6. Toussaint Millet, Eric, Indonesia: historia de una quiebra orquestada por el FMI y el Banco Mundial, Comité para la Anulación de la Deuda del Tercer Mundo, 29 de agosto de 2005; www. cadtm.org.

7. Office of the United States Trade Representative, Foreign Trade Barriers; http://www. ustr.gov/assets/Document-Library/Reporta_Publications/2004, fecha de revisión de la publicación, julio de 2007.

8. El APEC, fundado en 1989, en la actualidad está integrado por: Australia, Brunei Darussalam, Canadá, Chile, China, Corea, Estados Unidos, Filipinas, Hong Kong, China, Indonesia, Japón, Malasia, México, Nueva Zelandia, Papua Nue- 
va Guinea, Perú, Rusia, Singapur, Tailandia, Taipei Chino y Vietnam.

9. omc, Examen de las Políticas Comerciales de Indonesia, op. cit.

10. Organización Mundial del Comercio, op. cit.
11. Soesastro, Hadi, "Towards a Us-Indonesia Free Trade Agreement", Economics Working Paper Series, a draft the Enterprise for ASEAN Initiative (EAI) Study, 2004, http://www.csis.or.id/papers/ spe085.

12. Organización Mundial del Comercio, op. cit.

13. Organización Mundial del Comercio, ibíd.

\section{Anexo de cuadros estadísticos}

\section{Cuadro 1}

Indonesia: indicadores econónicos, 1980-2006

(Crecimiento y porcentajes con base en millones de dólares)

\begin{tabular}{|c|c|c|c|c|c|c|c|c|c|}
\hline Año & 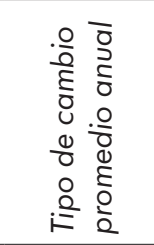 & 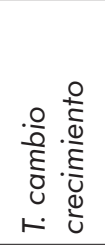 & 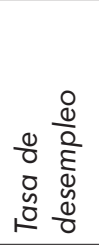 & 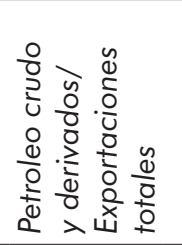 & 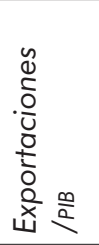 & 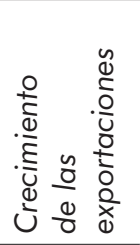 & 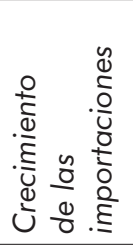 & 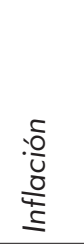 & 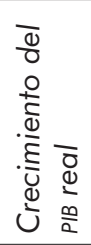 \\
\hline 1980 & 627.0 & 0.6 & & 58.7 & 30.2 & & & & \\
\hline 1981 & 631.8 & 0.8 & & 64.6 & 24.2 & 1.6 & 22.5 & & \\
\hline 1982 & 661.4 & 4.7 & & 66.7 & 23.6 & 0.1 & 27.0 & & \\
\hline 1983 & 909.3 & 37.5 & & 63.7 & 24.8 & -5.1 & -3.0 & & \\
\hline 1984 & $1,025.9$ & 12.8 & & 55.2 & 25.0 & 3.5 & -15.1 & & \\
\hline 1985 & $1,110.6$ & 8.3 & & 41.3 & 21.3 & -15.1 & -26.1 & & \\
\hline 1986 & $1,282.6$ & 15.5 & & 32.1 & 20.1 & -13.5 & 4.4 & & \\
\hline 1987 & $1,643.8$ & 28.2 & & 34.5 & 22.6 & 6.6 & 20.3 & & \\
\hline 1988 & $1,685.7$ & 2.5 & & $\ldots$ & 23.1 & 13.6 & 2.8 & & \\
\hline 1989 & $1,770.1$ & 5.0 & & 22.4 & 23.5 & 13.8 & 24.1 & & \\
\hline 1990 & $1,842.8$ & 4.1 & & 25.2 & 24.2 & 15.9 & 32.8 & & \\
\hline 1991 & $1,950.3$ & 5.8 & 2.6 & 19.7 & 25.1 & 13.5 & 18.5 & & \\
\hline 1992 & $2,029.9$ & 4.1 & 2.7 & 17.2 & 24.4 & 16.6 & 5.5 & & \\
\hline 1993 & $2,087.1$ & 2.8 & 2.8 & 13.6 & 23.3 & 8.4 & 3.8 & & \\
\hline 1994 & $2,160.8$ & 3.5 & 4.4 & 15.0 & 22.6 & 8.8 & 12.9 & & \\
\hline 1995 & $2,248.6$ & 4.1 & $\ldots$ & 14.2 & 22.5 & 13.4 & 27.0 & & \\
\hline 1996 & $2,342.3$ & 4.2 & 4.0 & 14.5 & 21.9 & 9.7 & 5.7 & & \\
\hline 1997 & $2,909.4$ & 24.2 & 4.7 & 12.1 & 26.1 & 13.0 & -2.9 & & \\
\hline 1998 & $10,013.6$ & 244.2 & 5.5 & 8.5 & 52.8 & -10.5 & -34.4 & & \\
\hline 1999 & $7,855.2$ & -21.6 & 6.4 & 7.5 & 36.6 & 1.7 & -12.2 & & \\
\hline 2000 & $8,421.8$ & 7.2 & 6.1 & 11.9 & 39.6 & 27.6 & 81.6 & & 4.8 \\
\hline 2001 & $10,260.9$ & 21.8 & 8.1 & 12.3 & 34.4 & -13.7 & -28.9 & 10.0 & 4.4 \\
\hline 2002 & $9,311.2$ & -9.3 & 9.1 & 11.3 & 29.0 & 3.0 & 0.9 & 5.2 & 4.7 \\
\hline 2003 & $8,577.1$ & -7.9 & 9.6 & 11.7 & 25.7 & 5.1 & 4.2 & 6.4 & 5.0 \\
\hline 2004 & $8,938.9$ & 4.2 & 9.9 & 11.2 & 27.9 & 17.2 & 42.7 & 17.1 & 5.7 \\
\hline 2005 & $9,704.7$ & 8.6 & 11.2 & 6.6 & 29.5 & 18.2 & 49.4 & 6.6 & 5.5 \\
\hline 2006 & & & 10.3 & & $\ldots$ & 16.5 & 8.9 & & $\ldots$ \\
\hline
\end{tabular}

Fuente: Elaboración propia con base en datos del International Monetary Found, International Financial Statistics, Yearbook, varios números. 
Cuadro 2

Indonesia: comercio con sus principales socios, 2001-2005 (valor en porcentajes con base en millones de dólares)

\begin{tabular}{lrrrrr}
\hline & \multicolumn{5}{c}{ Exportaciones (FOB valor por país de destino) } \\
\hline Total (millones de dólares) & 2001 & 2002 & 2003 & 2004 & 2005 \\
\hline Total & $56,316.8$ & $57,158.8$ & $61,058.2$ & $64,483.5$ & $85,659.9$ \\
\hline APEC & 100.0 & 100.0 & 100.0 & 100.0 & 100.0 \\
\hline Japón & 70.3 & 69.9 & 70.5 & 67.7 & 71.8 \\
Estados Unidos & 23.1 & 21.1 & 22.3 & 15.9 & 21.1 \\
Singapur & 13.8 & 13.2 & 12.1 & 13.6 & 11.5 \\
Corea del Sur & 9.5 & 9.4 & 8.8 & 9.3 & 9.1 \\
China & 6.7 & 7.2 & 7.1 & 5.3 & 8.3 \\
Malasia & 3.9 & 5.1 & 6.2 & 7.1 & 7.8 \\
Australia & 3.2 & 3.6 & 3.9 & 4.7 & 4.0 \\
Tailandia & 3.3 & 3.4 & 2.9 & 2.9 & 2.6 \\
Hong Kong & 1.9 & 2.1 & 2.3 & 3.1 & 2.6 \\
Filipinas & 2.3 & 2.2 & 1.9 & 2.2 & 1.7 \\
Vietnam & 1.4 & 1.4 & 1.5 & 1.9 & 1.7 \\
Canadá & 0.6 & 0.7 & 0.8 & 0.9 & 0.8 \\
Otros & 0.7 & 0.7 & 0.6 & 0.7 & 0.5 \\
\hline
\end{tabular}

Importaciones (CIF valor por país de origen)

\begin{tabular}{lrrrrr}
\hline Total (millones de dólares) & $30,962.1$ & $31,288.8$ & $32,550.7$ & $42,947.7$ & $57,700.9$ \\
\hline Total & 100.0 & 100.0 & 100.0 & 100.0 & 100.0 \\
\hline APEC & 63.7 & 63.9 & 64.9 & 66.0 & 68.9 \\
\hline Japón & 15.1 & 14.1 & 13.0 & 14.2 & 12.0 \\
Singapur & 10.2 & 13.1 & 12.8 & 11.2 & 16.4 \\
China & 6.0 & 7.8 & 9.1 & 9.5 & 10.1 \\
Estados Unidos & 10.4 & 8.5 & 8.3 & 7.5 & 6.7 \\
Corea del Sur & 7.1 & 5.3 & 4.7 & 4.5 & 5.0 \\
Tailandia & 3.2 & 3.8 & 5.2 & 6.5 & 6.0 \\
Australia & 5.9 & 5.1 & 5.1 & 5.2 & 4.4 \\
Malasia & 3.2 & 3.3 & 3.5 & 3.9 & 3.7 \\
Canadá & 1.2 & 1.3 & 1.0 & 1.3 & 1.2 \\
Vietnam & 0.6 & 0.8 & 1.3 & 1.0 & 0.8 \\
Brunei D. & 0.1 & 0.1 & 0.4 & 0.7 & 2.1 \\
Hong Kong & 0.8 & 0.8 & 0.7 & 0.6 & 0.5 \\
\hline Otros & 36.3 & 36.1 & 35.1 & 34.0 & 31.1 \\
\hline
\end{tabular}

Fuente: Indonesia Economic Statistics: http://www.geoinvestor.com/statistics. 


\section{Cuadro 3}

Indonesia: exportaciones de mercancías por grupos de productos, 2001-2005 (millones de dólares de EEUU y porcentajes)

\begin{tabular}{lrrrrr}
\hline & 2001 & 2002 & 2003 & 2004 & 2005 \\
\hline Exportaciones totales (millones de dólares) & $56,316.8$ & $57,158.7$ & $61,058.2$ & $64,483.5$ & $85,659.9$ \\
\hline Total \% & 100.0 & 100.0 & 100.0 & 100.0 & 100.0 \\
Productos primarios & 43.3 & 45.4 & 47.7 & 44.1 & 52.9 \\
Agricultura & 12.5 & 15.8 & 16.3 & 19.2 & 16.7 \\
Materias primas agrícolas & 3.6 & 4.3 & 5.0 & 5.6 & 5.1 \\
Minería & 30.8 & 29.6 & 31.4 & 24.9 & 36.1 \\
\hline Manufacturas & 56.0 & 54.1 & 51.8 & 55.5 & 46.9 \\
Hierro y acero & 0.7 & 0.7 & 0.9 & 1.3 & 1.1 \\
Productos químicos & 5.0 & 5.2 & 5.5 & 6.2 & 5.2 \\
Otras semimanufacturas & 11.9 & 11.6 & 10.7 & 11.0 & 8.7 \\
Maquinaria y equipo de transporte & 16.2 & 17.1 & 16.0 & 17.9 & 15.9 \\
Máquinas de oficina y eq. de telecomunic. & 10.5 & 10.7 & 9.1 & 10.2 & 7.9 \\
Maquinaria generadora de energía & 0.5 & 0.6 & 0.7 & 0.6 & 0.5 \\
Maquinaria eléctrica & 3.0 & 3.1 & 3.3 & 3.6 & 3.7 \\
Maquinaria no eléctrica & 0.9 & 1.1 & 1.1 & 1.4 & 1.5 \\
Otros & 1.3 & 1.6 & 1.8 & 2.1 & 2.3 \\
\hline Otros & 22.2 & 19.5 & 18.7 & 19.1 & 16.0 \\
Textiles & 5.7 & 5.1 & 4.8 & 4.9 & 4.0 \\
Prendas de vestir & 8.0 & 6.9 & 6.7 & 6.9 & 6.0 \\
Otros bienes de consumo & 8.4 & 7.4 & 7.2 & 7.4 & 6.0 \\
\hline Otros productos & 0.8 & 0.6 & 0.5 & 0.4 & 0.3 \\
\hline Furte: & & &
\end{tabular}

Fuente: WTO, Examen de las Políticas Comerciales de Indonesia, 2007 
$\underline{\text { Análisis }}$

Cuadro 4

Indonesia: importaciones de mercancias por grupos de productos, 2001-2005 (millones de dólares de EEUU y porcentaje)

\begin{tabular}{lrrrrr}
\hline & \multicolumn{1}{c}{2001} & 2002 & 2003 & 2004 & 2005 \\
\hline \multicolumn{1}{c}{ Total \% } & $30,962.1$ & $31,288.8$ & $32,550.6$ & $42,947.7$ & $57,700.9$ \\
\hline Productos primarios & 100.0 & 100.0 & 100.0 & 100.0 & 100.0 \\
\hline Agricultura & 38.8 & 41.1 & 43.4 & 38.5 & 45.2 \\
Productos alimenticios & 17.3 & 16.8 & 16.7 & 15.5 & 11.5 \\
Materias primas agrícolas & 9.9 & 11.1 & 11.4 & 10.5 & 8.1 \\
Minería & 7.4 & 5.8 & 5.3 & 5.0 & 3.5 \\
Combustibles & 21.5 & 24.2 & 26.7 & 23.1 & 33.7 \\
\hline Manufacturas & 17.8 & 21.0 & 23.5 & 19.1 & 30.0 \\
Hierro y acero & 61.1 & 58.8 & 56.5 & 61.4 & 54.8 \\
Productos químicos & 4.0 & 4.5 & 4.4 & 6.5 & 6.7 \\
Otras semimanufacturas & 17.4 & 16.9 & 16.3 & 17.7 & 14.0 \\
Maquinaria y equipo de transporte & 4.4 & 4.6 & 4.7 & 4.4 & 4.0 \\
Máquinas de oficina y eq. de telecomunic. & 29.2 & 27.5 & 26.3 & 28.3 & 26.5 \\
Maquinaria eléctrica & 2.5 & 3.0 & 3.5 & 4.2 & 3.6 \\
Maquinaria no eléctrica & 2.2 & 2.0 & 2.1 & 2.2 & 2.1 \\
Productos de la industria del automóvil & 12.4 & 12.1 & 10.0 & 11.4 & 10.6 \\
Equipos de transporte & 5.2 & 4.7 & 5.5 & 5.6 & 5.4 \\
Otros & 6.0 & 4.8 & 4.1 & 3.8 & 3.4 \\
\hline Textiles & 0.9 & 0.9 & 1.1 & 1.1 & 1.4 \\
Prendas de vestir & 3.5 & 2.8 & 2.0 & 1.7 & 1.3 \\
Otros bienes de consumo & 0.1 & 0.1 & 0.1 & 0.1 & 0.1 \\
\hline Otros productos & 2.3 & 2.4 & 2.6 & 2.5 & 2.2 \\
\hline
\end{tabular}

Fuente: WTO, Examen de las Políticas Comerciales de Indonesia, 2007. 